\title{
Study on the Morphological Characters of 25 Soy- bean Varieties in Terms of Interaction with Nitro- gen-Fixing Bacteria Indigenous to SCDA Turda
}

\author{
Zamfira DINC $\breve{A}^{1}$, Roxana VIDICAN ${ }^{1}$, Ioan ROTAR ${ }^{1}$, Eugen MUREŞANU ${ }^{2}$ \\ ${ }^{1}$ Faculty of Agriculture, UASMV Cluj-Napoca, Calea Mănăștur 3-5, Cluj-Napoca, Romania \\ ${ }^{2}$ Agricultural Research \& Development Station Turda, Agriculturii st., No.27, 401100, Turda \\ *corresponding author: roxana.vidican@usamvcluj.ro \\ Bulletin USAMV series Agriculture 71(2)/2014 \\ Print ISSN 1843-5246; Electronic ISSN 1843-5386 \\ DOI 10.15835/buasvmcn-agr: 10887
}

\begin{abstract}
Our study aimed to underline the morphological characters of 25 soybean varieties of both Romanian and foreign origin in the ecopedological background of SCDA Turda in the presence of a nitrogen-fixing bacteria indigenous to the soil. Activities undertaken to reach this goal encompassed carrying out biometrical determinations of the plants (root length, plant height and number of leaves) and registering the number of nodules for each separate variety. Analyzing the data regarding the afore-mentioned parameters revealed significant morphological differences between the varieties, all of which were statistically relevant.
\end{abstract}

Keywords: soybean varieties, nodules number, root length, leaves number, plant height

\section{INTRODUCTION}

Soybean (Glycine max (L.) Merrill) serves as one of the most valuable crops in the world and is also known as the "Golden bean" and miracle crop of the $20^{\text {th }}$ century. Moreover, soybean has become famous as the plant that will help feed the world's present and future population and help solving the global protein deficiency (Maingi, 2006). The global soybean production increased by $4.6 \%$ annually from 1961 to 2007 and reached average annual production of 217.6 million tons in 2005-07. World-wide production of soybeans is predicted to increase by $2.2 \%$ annually to 371.3 million tons by 2030 (Masuda and Goldsmith, 2009).

Due to its great nutritional importance, special attention is given to the process of species amelioration, to refining crop technologies and activities to combat diseases and pests, and also to the improvement of symbiotic nitrogen fixation in this plant. Knowing that symbiotic fixation is a complex physiological process influenced by the interaction of genetic elements in the higher plant species and Rhizobia association
(Hungria and Bohrer, 2000; Sanginga et al., 2000; Sinclair et al., 1991; Pulver et al., 1982, cited by Gwata, 2003), undertakings aiming to study the morphologic diversity of as many varieties of soybean in relation to various nitrogen fixating strains are considered to be of great prospect. This is the reason for which our study's goal was to underline the morphological characters of 25 soybean varieties of both Romanian and foreign origin in the ecopedological background of SCDA Turda in the presence of a nitrogen-fixing bacteria indigenous to the soil.

\section{MATERIALS AND METHODS}

The experiment took place in 2012, in the experimental field of SCDA Turda, with cambic phaeozem soil type, in 25 variants and three repetitions, using the Latin rectangle method. The biological material used for our study consisted of 25 soybean varieties belonging to several maturity groups, of Romanian and foreign origin (Table 1). During the growing season, all necessary technological measures respecting specific soybean crop technology were applied. 
At 6 weeks after sowing, which coincided with the flowering period (when $50 \%$ of plants were flowering) samples were taken (five plants of each variant in three repetitions) to study the morphological characters of the plants.

Biometric determinations of plants: root length, nodules number, size and number of leaves, respectively, were made according to the methodology proposed by P. J. Hoben Somasegaran in 1985. Statistical interpretation of data was done with data processing software StatSoft Statistics.

\section{RESULTS AND DISCUSSIONS}

Comparative analysis of root development revealed the existence of a strong variation of this trait in all 25 studied species (Fig. 1., A). Significant differences were observed between varieties 3 and 10 from the variety 16 . A similar case is found in variety 18 which was superior both to the variety of varieties 16 and 2, 7, 12, 20, 23, 25, the differences being statistically very significant. In terms of the 3 varieties considered as superior, root length exceeds $22 \mathrm{~cm}$ (varieties 3 to 10) and $24 \mathrm{~cm}$ in variety 18 . For this reason, the variety 18 is rated as having the strongest root development in terms of experimentation. At the opposite pole, we have variety 16 whose root does not exceed 14 $\mathrm{cm}$.

Significant differences were reported after comparing the variety 3 and 7 and the comparison of three varieties of the same kind 20, 23, 25 (Fig. 1., B). Under the same aspect of the significant differences, we distinguish that the variety 10 is superior to varieties $7,20,23,25$. Inferiority of varieties is seen very well in comparing varieties $2,8,11,12,13,14,15,19,24$ with variety 18 , the differences observed being significant.

An interesting case is revealed when comparing variety 1 with varieties 18 and 16, the differences being statistically significant (Fig. 1., A). Compared to variety 18 , variety 1 proved inferior, but compared to the variety 1 , the latter proves its superiority. Between variety 2 and the varieties 3 and 10 were also recorded significant differences. Compared to the varieties 3 , with the same significant differences, varieties $8,11,12,13$, $14,15,19$ and 24 were found to be inferior. Length over $20 \mathrm{~cm}$ of the root of variety 4 was significantly higher than the values recorded for varieties 7 , $16,20,23$. The same observation can be made in the case of variety 18 where when compared to varieties 5, 6, 9 and 17 were found to be inferior as their root length were shorter by at least $5 \mathrm{~cm}$ than the value recorded in plants of the variety 18 .

8 varieties $(2,8,11,12,13,14,15,19,24)$ have been shown to be inferior to variety 10 from the point of view of the length of the root. This parameter has been shown statistically.

Root value of about $14 \mathrm{~cm}$ observed in the varieties $7,16,23$ was significantly lower than the length of $20 \mathrm{~cm}$ recorded in the variety 21 . A similar situation was found when comparing the variety 16 to variety 17.

Tab.1. Varieties used as biological material and their origin

\begin{tabular}{llllll}
\hline Variety Name & Origin & Variety Name & Origin & Variety Name & Origin \\
\hline Diamant & SCDA Turda & Cristina $\boldsymbol{T D}$ & SCDA Turda & Crusader & Foreign origin \\
\hline $\boldsymbol{P e r l a}$ & SCDA Turda & Malina $\boldsymbol{T D}$ & SCDA Turda & Dekabig & Foreign origin \\
\hline Agat & SCDA Turda & Danubiana & INCDA Fundulea & Asgrow & Foreign origin \\
\hline Safir & SCDA Turda & Columna & INCDA Fundulea & Clamir & Foreign origin \\
\hline Eugen & SCDA Turda & Triumf & INCDA Fundulea & $\mathbf{9 2 B 6 3}$ & Foreign origin \\
\hline Eugen & SCDA Turda & Românesc $\mathbf{9 9}$ & INCDA Fundulea & Sapporo & Foreign origin \\
\hline Onix & SCDA Turda & Daciana & INCDA Fundulea & Tairo & Foreign origin \\
\hline Felix & SCDA Turda & Atlas & INCDA Fundulea & Isidor & Foreign origin \\
\hline Darina $\boldsymbol{T D}$ & SCDA Turda & & & & \\
\hline
\end{tabular}



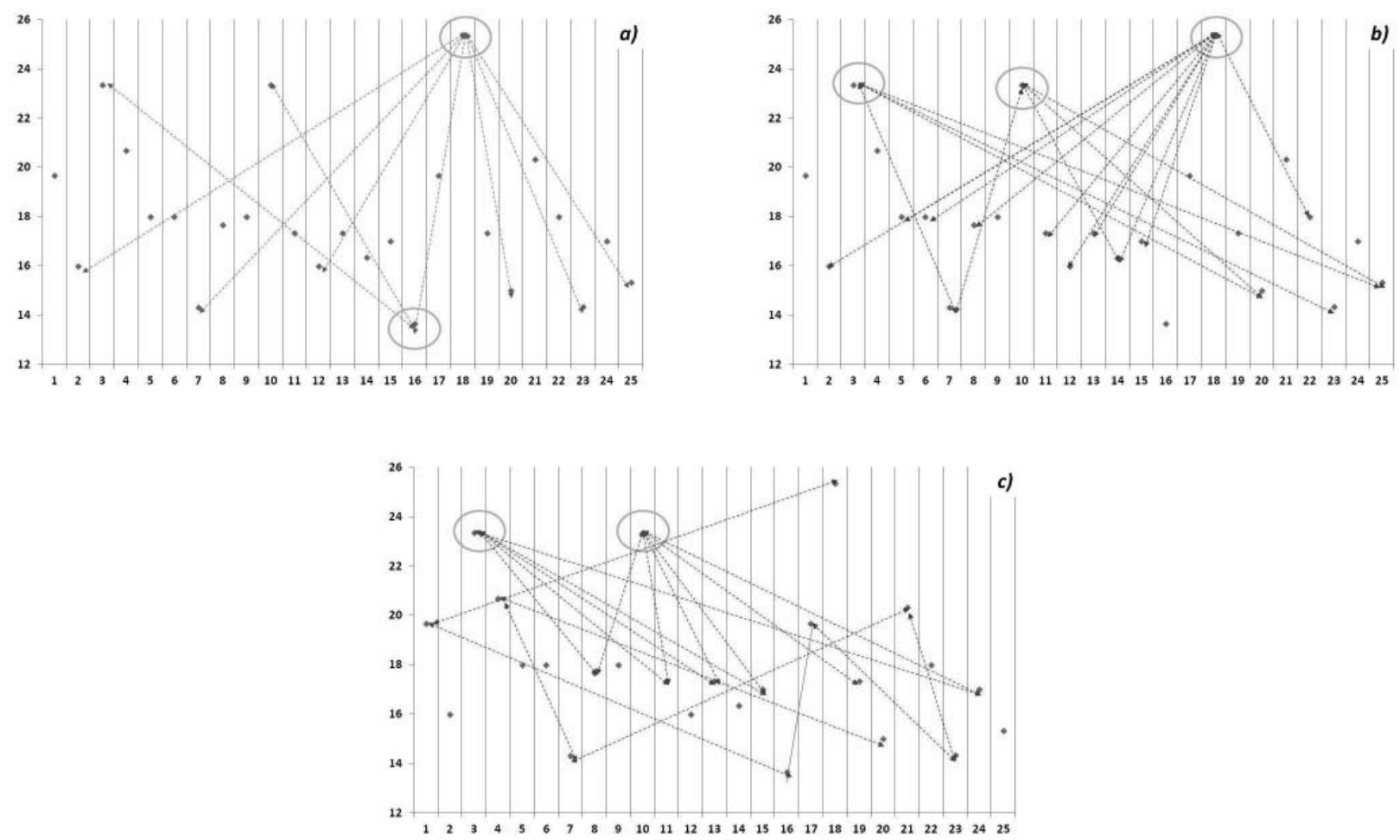

Fig. 1. Variation of the rooth length under the influence of a indigenous rhizobial factor

$$
\left.\mathrm{p}<0.001^{* * *} / \text { b) } \mathrm{p}<0.01^{* *} / \mathrm{c}\right) \mathrm{p}<0.05^{*}
$$

1 - Diamant, 2 - Perla, 3 - Agat, 4 - Safir, 5 - Eugen, 6 - Onix, 7 - Felix, 8 - Darina TD, 9 - Cristina

TD, 10 - Malina TD, 11 - Danubiana, 12 - Columna, 13 - Triumf, 14 - Romanesc 99, 15 - Daciana, 16 - Atlas, 17 - Crusader, 18 - Dekabig, 19 - Asgrow, 20 - Clamir, 21 - PRM91M10, 22 - 92B63, 23 - Sapporo, 24 - Tairo, 25 - Isidor

Analyzing the number of nodules on the root system of each variety, strong variations of this character can be found in the varieties found in the study. Compared to variety 1 , none of the varieties registered a significant difference, but significant differences from one variety are seen in varieties 6 and 14 . Varieties 12,13,18 and 19, compared to the same variety 1 , registered significant differences. Variety 2 compared to variety 6 registers a highly significant difference while variety 16 shows a significant difference when compared to variety 2 . The only variety that is a significant difference from the variety 2 is the variety in September. Variety 3 compared to variety 14 shows a highly significant difference, while varieties 12, 13, 18 and 19 show significant differences. Significant differences from variety 3 have been observed in compassion with varieties $6,8,11,20,21,22$, all differences being statistically relevant.
In terms of variety 4 , none of the species has recorded a highly significant difference compared to it; however, the variety 6 shows a significant distinct difference in comparison to variety 4 . Significant differences between varieties 12 , 14,16 were observed against variety 4 (Tab. 2.). Concerning variety 5 , no significant difference has been observed, however significant differences can be seen in the varieties 13, 14, 18 and 19. Compared to the same variety 5 , very significant differences are found in the varieties 6, 12, 21 and 22.

Of all the varieties taken in the study, in terms of the number of nodules, the most significant differences are found when comparison is made to variety 6 , to which varieties $8,11,12,13,14,15,18$, $19,20,21,22,23$ have shown inferiority. Varieties 10, 17 and 24 show significant differences, while varieties 7 and 25 stand out in a significant 


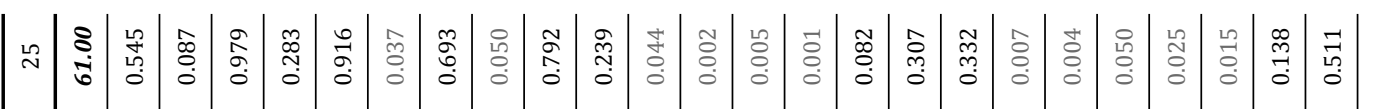

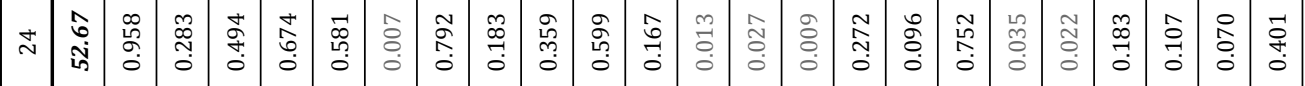

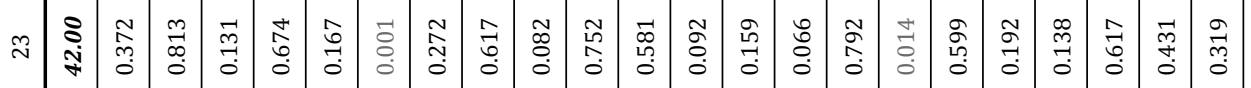

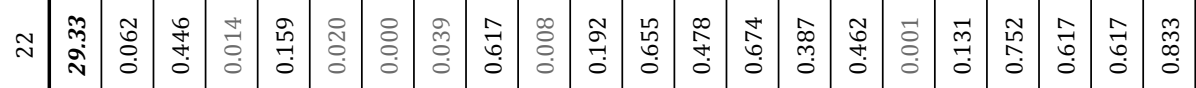

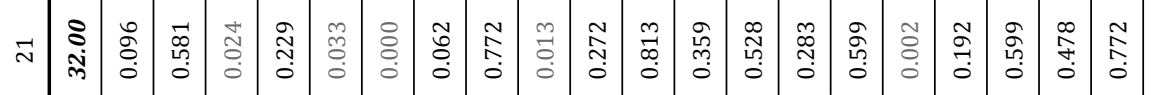

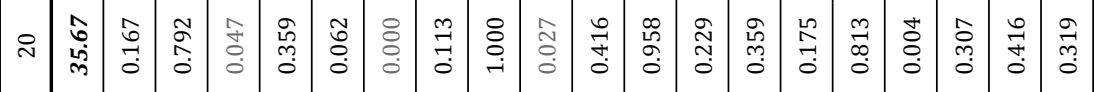

2 2)

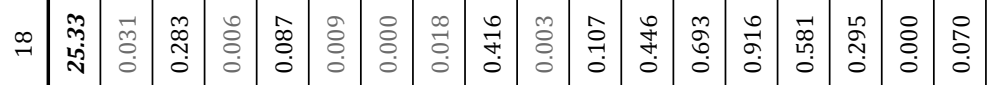

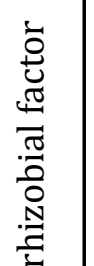

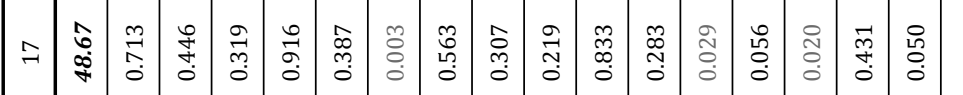

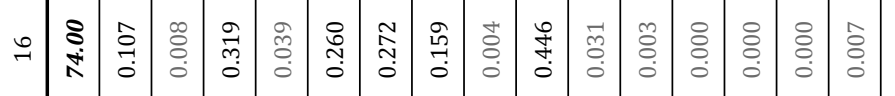

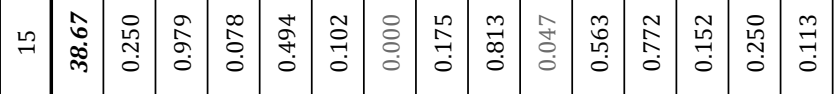

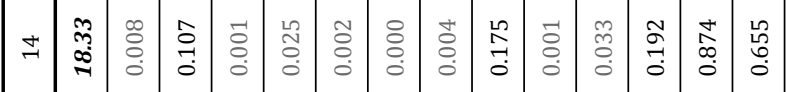

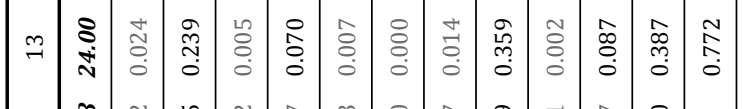

$\approx$ ح

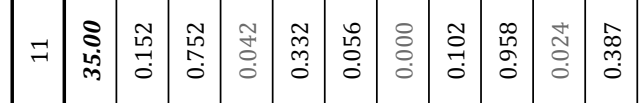

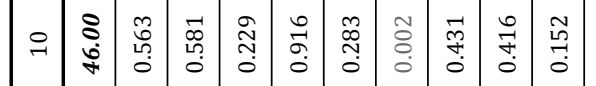

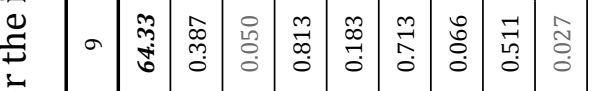

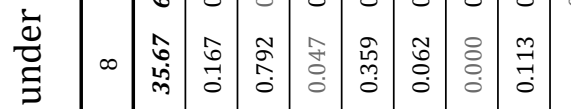

苟

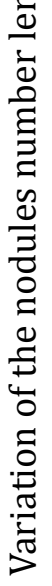

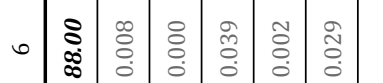

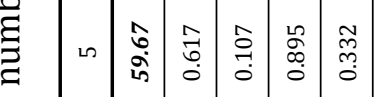

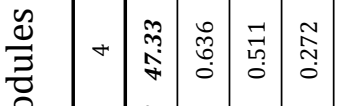

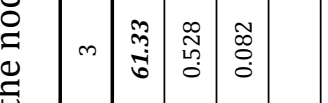

E

莡

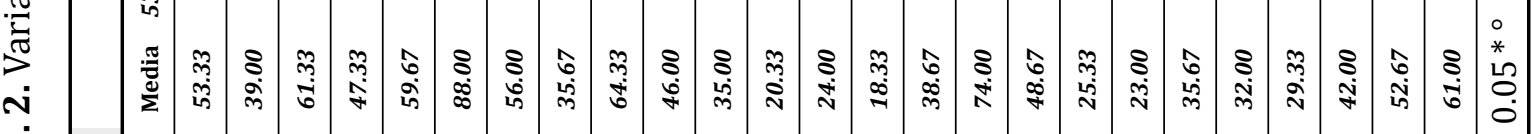

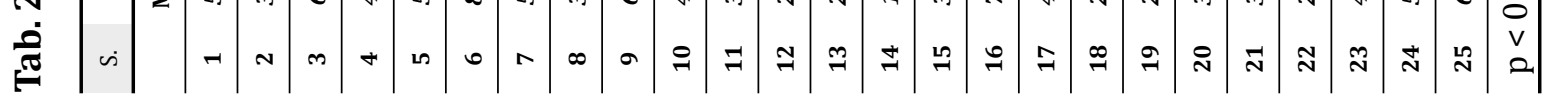


difference in the number of nodules from variety 6. Compared to variety 7 , varieties 12 and 14 present distinctly significant differences, while the significant differences to variety 7 were registered in varieties 13, 18, 19 and 22; the registered differences are statistically significant. With regards to variety 8 , a single variety (variety 16 ) registered a distinctly significant difference, while varieties 9 and 25 show a significant difference compared to variety 8 .

Variety 9 presents a very significant difference from varieties 12 and 14, while it registers a distinctly significant difference from the varieties $13,18,19$ and 22 . Compared to variety 9 , varieties $11,15,20$ and 21 show a significant difference in the number of nodules (Tab. 2.). Compared to variety 10 , all studied varieties show neither a very significant difference, nor a distinctly significant difference; only varieties 12,14 and 16 register a significant difference from variety 10 . Variety 11 shows a distinctly significant difference from variety 16 and a significant difference from variety 25 . Variety 12 shows a very significant difference from variety 16 , a distinctly significant difference from variety 25 and a significant difference from varieties 17 and 24 .

Compared from variety 13 , variety 16 registers a very significant difference, while varieties 24 and 25 present a distinctly significant difference, and a significant difference, respectively, from the same variety 13 (Tab. 2.). Two very significant differences are noticeable between variety 14 and varieties 16 and 25 , while varieties 17 and 24 show a significant difference, and a distinctly significant difference, respectively, from the same variety 14 . In the case of variety 15 , there is a single distinctly significant difference from variety 16 . Variety 16 registers a very significant difference from varieties 18, 19 and 22, distinctly significant differences from varieties 20 and 21 and significant differences from varieties 17 and 23.

Variety 17 shows one significant difference from variety 19, while variety 18 shows a distinctly significant difference from variety 25 and a significant difference from variety 24 (Tab. 2.). Variety 19 also registers a distinctly significant difference from variety 25 and a significant difference from variety 24 . Varieties 20, 21 and 22 register significant differences from variety 25 , which are statistically relevant.
Analyzing varieties from the point of view of plant height emphasises very significant, distinctly significant and significant differences in all varieties comprised in this study (Tab. 3.). Thus, when compared to variety 1, varieties 6 and 15 present very significant differences, varieties 3 and 16 register distinctly significant differences, and varieties 5 and 7 show significant differences. Compared to variety 2 , a single variety (variety $15)$ presents a distinctly significant difference, while varieties $6,14,16,18$ and 21 underline a significant difference from variety 2 .

In the case of variety 3 , we have observed a very significant difference from varieties $8,14,17$, $18,19,21,22,24$ and 25 , a distinctly significant difference from varieties 10,12,13and 23 and a significant difference of variety 20 from variety 3 (Tab. 3.). Significant differences arise also when comparing variety 4 to varieties $6,8,14,15,18,19$ and 25 , from which the former variety is superior in plant height (except varieties 6 and 15, which are superior to variety 4 ).

Variety 5 presents a number of 6 very significant differences when compared to varieties $8,14,18,19,21$ and 25 , while varieties $24,22,17$, 12 and 10 register distinctly significant differences from variety 5 (Tab.3.). In the case of varieties 13 , 20 and 23, these show significant differences from the same variety 5 .

Compared to variety 6 , a number of 11 varieties $(8,10,12,14,17,18,19,21,22,24$ and 25$)$ register very significant differences, while varieties 23, 20 and 13, present distinctly significant differences when compared to variety 6 (Tab. 3.). Very significant differences are also observed by comparing variety 7 to varieties $8,14,18,19$ and 21 , and distinctly significant differences register when comparing this variety to varieties 25,24 , 22 and 17. Significant differences from variety 7 are noticed when comparing it to varieties 10,12 , 13, 20 and 23.

Compared to variety 8 , varieties 15 and 16 present very significant differences; variety 9 compared to variety 8 registers distinctly significant differences, while variety 11 shows significant differences from variety 8 (Tab.3). Variety 9 compared to varieties 19 and 21 underlines a very significant difference, compared to varieties 14, 18 and 25 shows a distinctly significant difference, and varieties 10, 12, 17, 22 and 24 present a significant difference from variety 


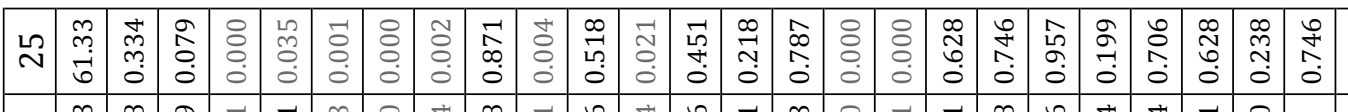

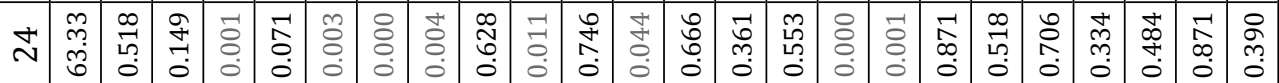

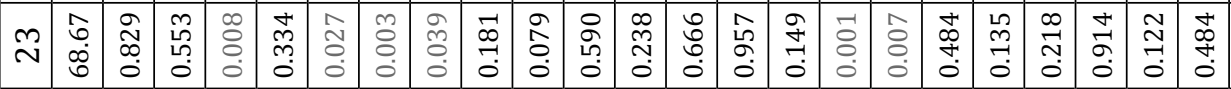

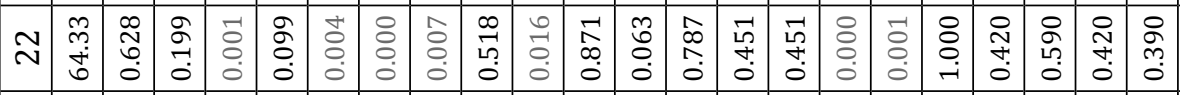

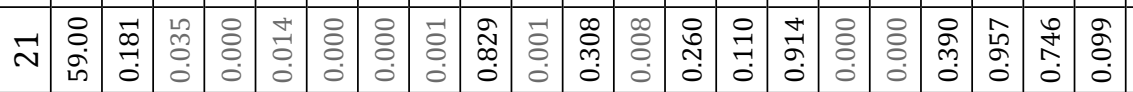

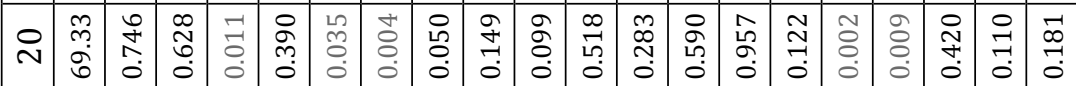

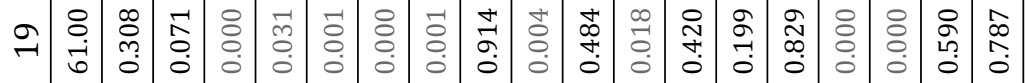

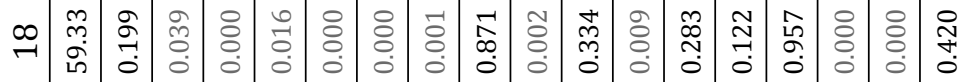

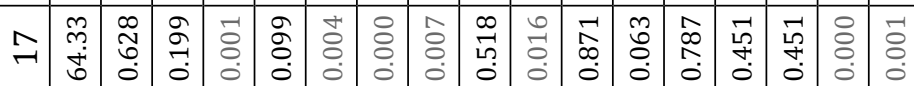

닌

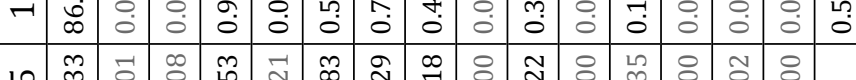

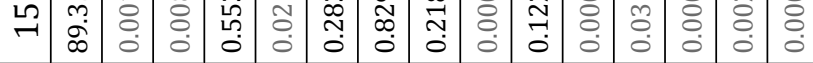

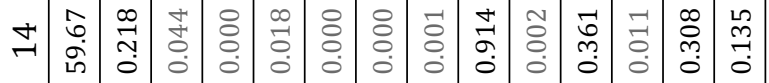

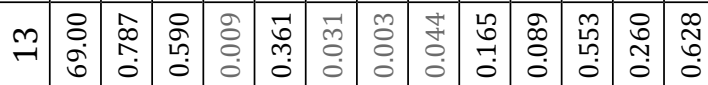

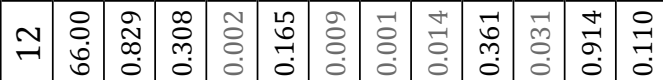

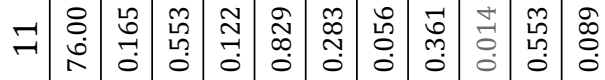

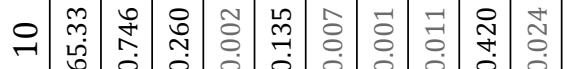

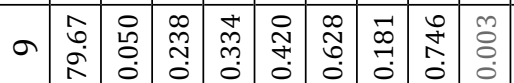

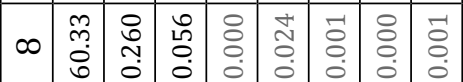

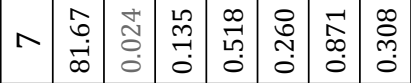

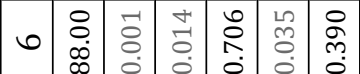

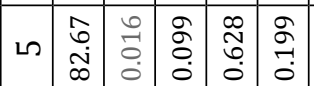

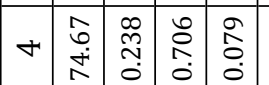

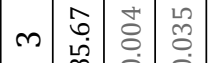

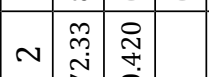

N 10

$-\underset{\substack{\infty \\ \hat{\sigma}}}{n}$

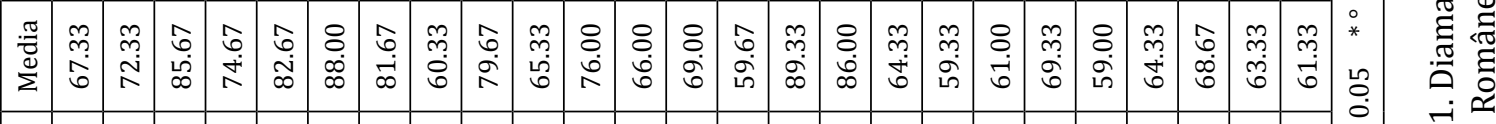

$\frac{1}{\pi}$

$\dot{s}$

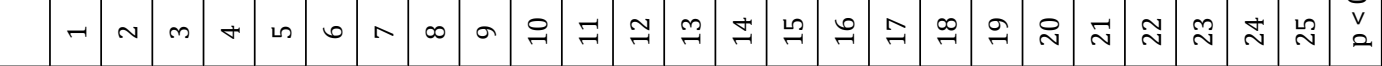


9. Very significant differences where registered when comparing variety 10 to varieties 15 and 16 .

When compared to varieties 18 and 21, variety 11 presents distinctly significant differences, unlike varieties 25, 24, 19, 15 and 14, which register significant differences when compared to the same variety 11 (Tab. 3). Very significant differences, and distinctly significant differences, respectively, are also registered by variety 12 from varieties 15 and 16, these being statistically relevant. Variety 13 compared to varieties 15 and 16 shows distinctly significant differences, while variety 14 , when compared to the same varieties 15 and 16, registers very significant differences.

In the case of variety 15 , there are reports of very significant differences when compared to varieties $17,18,19,21,22,23,24$ and 25 , a single variety (variety 20) showing a distinctly significant difference from variety 15 (Tab. 3). Very significant differences are also noticeable in the case of variety 16 , when compared to varieties 17 , $18,19,21,22,24$ and 25 , while the same variety 16 presents distinctly significant differences when compared to 20 and 23.
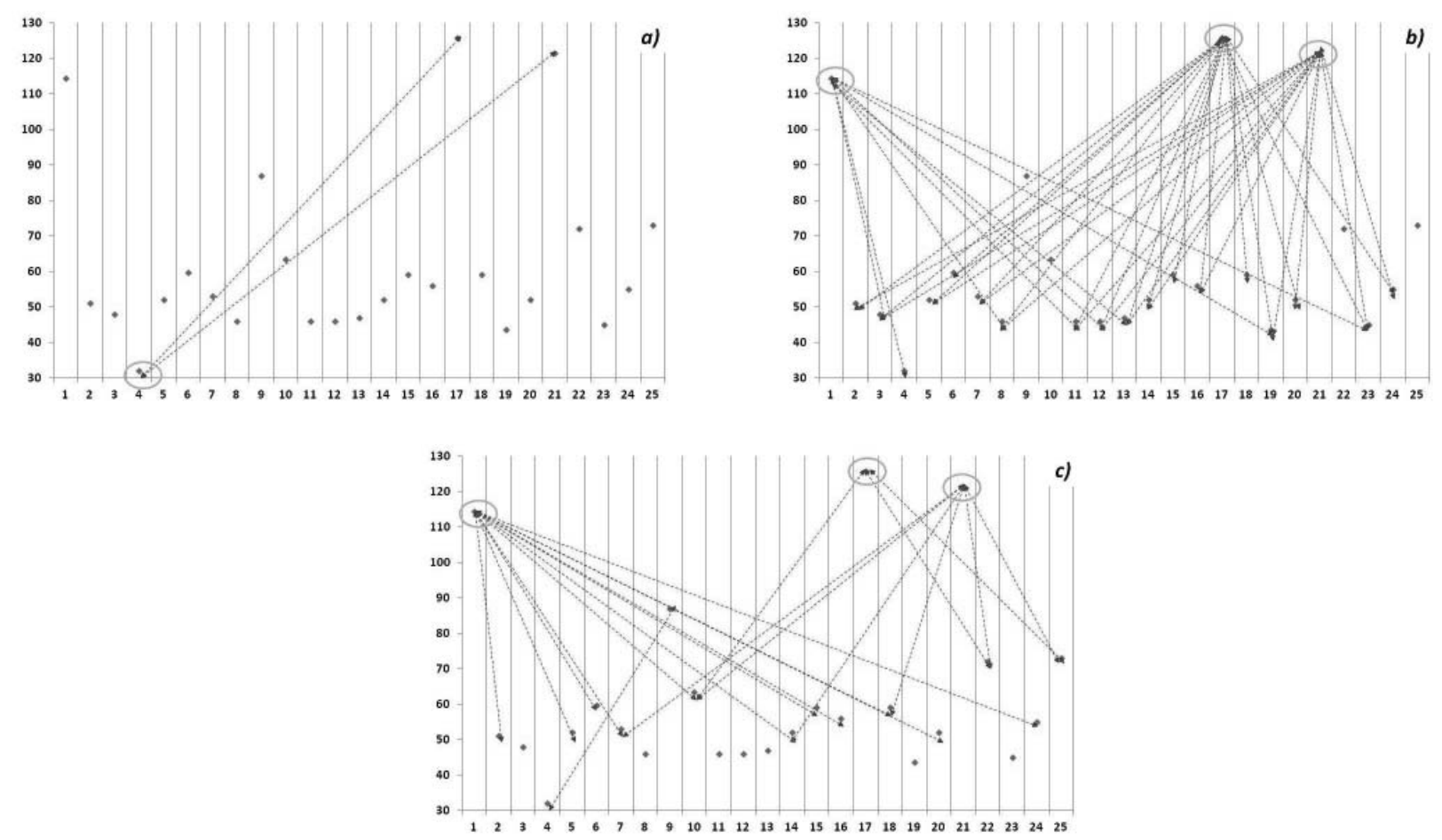

Fig. 2. Variation of the number of leaves under the influence of a indigenous rhizobial factor

$$
\left.\mathrm{p}<0.001^{* * *} / \text { b) } \mathrm{p}<0.01^{* *} / \mathrm{c}\right) \mathrm{p}<0.05^{*}
$$

1 - Diamant, 2 - Perla, 3 - Agat, 4 - Safir, 5 - Eugen, 6 - Onix, 7 - Felix, 8 - Darina TD, 9 - Cristina TD, 10 - Malina TD, 11 - Danubiana, 12 - Columna, 13 - Triumf, 14 - Romanesc 99, 15 - Daciana, 16 - Atlas, 17 - Crusader, 18 - Dekabig, 19 - Asgrow, 20 - Clamir, 21 - PRM91M10, 22 - 92B63, 23 - Sapporo, 24 - Tairo, 25 - Isidor 
of variety 9 proved superior to that of variety 4 , which presented only 32 leaves, the difference being statistically ensured as being significant. The inferiority to variety 17 is also observed in the case of varieties 10, 22 and 25, these varieties registering at least 60 leaves less that the plants belonging to the variety 17 . Also from the point of view of the number of leaves, varieties $7,10,14$, 18,22 and 25 show themselves inferior to variety 21 , the differences between these inferior varieties and the latter being of at least 75 leaves.

\section{CONCLUSIONS}

On the ecopedological background of SCDA Turda, we noticed important morphological variations registered between the varieties during the flowering season, under the influence of a nitrogen-fixating bacterium.

Root length in the studied varieties varies between 14 to $26 \mathrm{~cm}$, but only 3 varieties (Agat, Malina TD, Dekabig) surpass $22 \mathrm{de} \mathrm{cm}$.

The variation of the number of nodules was between the limits of an 18 to 88 interval, the majority of varieties occupying a median position inside this interval.

In 2012, the maximum height of soybean plants, registered in the experimental field, was of 89 de $\mathrm{cm}$ (Daciana variety). From this variety, a decrease of the height of $40 \mathrm{~cm}$ was noticed in the
PRM91M10 variety, which registered the smallest height.

The number of leaves was the parameter with the largest variation in the experimental field, the inferior limit of the interval being 30 leaves (Safir variety), the superior one, 130 leaves; in 3 varieties (Diamant, Crusader, PRM91M10) over a 110 leaves were noticed.

\section{REFERENCES}

1. Maigi J. M., N.M. Ditonga, C.A. Shisanya, B.Hornetz and G.M. Muluvi (2006). Population levels of indigenous Bradyrhizobia nodulating promiscuous soybean in two kenyan varietyls of the semi-arid and semi-humid agroecological zones. Journal of Agriculture and Rural Development in the Tropics and Subtropics Volume 107, No. 2, 2006, pages 149-159

2. Masuda T., Goldsmith P., D., (2009). World soybean production: area harvested, yield and long-term projections, International Food and Agribusiness Management Review, Vol. 12, Issue, pp. 143-161

3. Gwata E. T., Wofford D. S., Boote K. J., and Mushoriwa H., (2003). Determination of effective nodulation in early juvenile soybean plants for genetic and biotechnology studies, African Journal of Biotechnology Vol 2 (11), pp.417-420, November 2003, Available online at http:// www.academicjournals.org/AJB

4. Somasegaran P., Hoben J., (1985). Methods in legumeRhizobium technology, University of Hawaii NifTAL *Project and Mircen*, Hawai Institute of Tropical Agriculture and Hunan Resources, College of Tropical Agriculture and Hunan. Resources. 